to obtain eggs from the ovaries of women. This procedure was essential to the successful development of IVF.

Ten years after Edwards and Steptoe began their collaboration and after many unsuccessful attempts at IVF, Louise Joy Brown, the first 'test-tube' baby, was born 25 July 1978. A new field of clinical medicine, now called assisted reproduction, was also born on 25 July 1978. Since the birth of Louise Brown 23 years ago, nearly one million healthy babies have been born to infertile parents. In addition to IVF, the research of Edwards and Steptoe paved the way for four other new areas of clinical investigation: preimplantation diagnosis of genetic diseases, cryo-preservation of human embryos, intracytoplasmic sperm injection for treatment of male infertility and, most recently, human embryonic stem cell research for cell therapy of common disorders, such as Parkinson disease and Type 1 diabetes. The birth of Louise Brown also led to the new field of reproductive bioethics and law, which is especially timely given the current controversy surrounding human embryonic stem cell research.

Patrick Steptoe, Edwards' long-term clinical collaborator, died in 1988 at age 75 , one week before he was to be knighted at Buckingham Palace by Queen Elizabeth II. Were Steptoe alive today, he would have undoubtedly shared in this Lasker Award with Robert Edwards.

Most advances in clinical medicine are just that-an ad- vance-but a precious few are revolutionary. The way we know IVF was truly revolutionary is that in its early days Edwards and Steptoe were viciously attacked by the 'Holy Trinity': the Pope, the press and prominent Nobel Laureates. This millennial year, the UK issued four stamps to celebrate the most noteworthy British advances in clinical medicine over the last 1,000 years. Those honored were Edward Jenner, for vaccination against smallpox (1796), Florence Nightingale, for founding the field of nursing (1890), Alexander Fleming, for discovering penicillin (1928), and Robert Edwards, for developing IVF (1978). If one picture is worth 1,000 words, one's picture on a millennial stamp should be worth 1,000 Lasker Awards!

JOSEPH L. Goldstein Chair, Lasker Awards Jury

Lasker Award recipients receive an honorarium, a citation highlighting their achievements and an inscribed statuette of the Winged Victory of Samothrace, which is the Lasker Foundation's symbol of humankind's victory over disability, disease and death.

To read the formal remarks of speakers at the Lasker ceremony as well as detailed information on this year's awardees, please refer to the Lasker web site at www.laskerfoundation.org.

\title{
An inspiring leadership toward improving global health
}

Conventional wisdom suggests that it may take as long as 30 years from the 'eureka' of a basic medical research discovery to the availability of salutary treatment for a crippling disease or life-threatening illness, and then it may take yet another 30 years or more to create the right public health infrastructures that will make it possible to deliver this effective treatment to a living human being who can experience its health benefits. The 2001 Mary Woodard Lasker Award for Public Service honors an individual whose inventive concepts and dedication to saving lives and to alleviating human suffering from disease, over a lifetime of work, were not deterred by the political and social obstacles that often stand in the way of bringing medical treatments and cures to countless numbers of people, many of whom are living in remote parts of the world. The award recipient is
William H. Foege, former Director of both the Centers for Disease Control and the Carter Center.

Dr. Foege is honored for his exceptional leadership in the fight to eradicate smallpox from the world, and for his continuing battle to eliminate other major diseases including polio, guinea worm disease, measles, AIDS and 'river blindness'. His imaginative thinking and physical courage have been among his leadership qualities that made his campaign to bring the fruits of medical research to the people of the world, a dream of Mary Lasker, for whom this award is named. Dr. Foege is now a professor at Emory University and a senior advisor to the Melinda and Bill Gates Foundation.

Daniel E. Koshland JR

Chairman, Lasker Public Service Award Selection Committee 